\title{
REVIEW
}

\section{Vascular dysfunction and pathology: focus on mechanical forces}

\author{
Gloria Garoffolo (1) and Maurizio Pesce 10 \\ Unità di Ingegneria Tissutale Cardiovascolare, Centro Cardiologico Monzino, IRCCS, Via Parea, Milan, Italy \\ Correspondence should be addressed to G Garoffolo: gloria.garoffolo@ccfm.it
}

\begin{abstract}
The role of mechanical forces is emerging as a new player in the pathophysiologic programming of the cardiovascular system. The ability of the cells to 'sense' mechanical forces does not relate only to perception of movement or flow, as intended traditionally, but also to the biophysical properties of the extracellular matrix, the geometry of the tissues, and the force distribution inside them. This is also supported by the finding that cells can actively translate mechanical cues into discrete gene expression and epigenetic programming. In the present review, we will contextualize these new concepts in the vascular pathologic programming.
\end{abstract}

\section{Introduction}

Blood vessels undergo continuous structural changes in response to physiologic alterations, or wall injury. In particular, blood flow exerts a crucial role in vessel remodeling, starting from vascular system development to adult life. Indeed, in the early post-implantation life period, blood flow, acting on endothelial cells, promotes intracellular signaling cascades leading to the formation of a branched, hierarchical structure of vessels with large and small caliber (1). The implication of hemodynamic forces in the vasculature development is suggested by evidences showing that in embryos with abnormal cardiogenesis, vessels of the yolk sac fail to remodel, resulting in embryo lethality $(2,3)$. Blood flow also contributes to vessel maturation by the specification of the arterial vs the venous compartments. For example, in zebrafish and mice, endothelial progenitor cells express markers of both venous and arterial phenotype $(4,5)$, and the exposure to blood flow promotes an increase in arterial markers expression and a parallel downregulation of the venous genes, contributing in this way to the differentiation into arterial endothelial cells (ECs) (6). During the adult life, hemodynamic forces also play an important role in vessel homeostasis. Indeed, in physiological conditions, laminar shear stress, a tangential force acting on the endothelium, has vaso-protective effects, stimulating endothelial cells to release small molecules (e.g. nitric oxide) and cytokines with antithrombotic and vasodilator properties (7). An example of flow-dependent control of the vascular tone is the transcriptional regulation of genes encoding for mediators with vasodilator/vasoconstrictor effects, such as endothelial nitric oxide synthase, prostacyclin (NOS1,PTGIS) (8). Indeed, various mechanosensors exposed to shear stress, such as primary cilia, integrins, induce the activity of transcription factors, such as Kröppel-like factor (KLF2), thus promoting the expression of vascular tone-regulating genes (9). In the murine carotid artery collar model, it has been demonstrated that KLF2 is highly expressed in high-shear stress regions and this regulates the transcription of flow-responsive genes, such as endothelin-1, adrenomedullin, and nitric oxide synthase 
(eNOS), involved in controlling vascular tone(10). Although hemodynamic forces are considered determinants of vascular morphogenesis and physiology, it has been demonstrated that an altered blood flow, in conjunction with metabolic, genetic, or inflammatory-related diseases, may contribute to the pathological progression of the vascular tissue, such as atherosclerosis and vein graft disease $(11,12,13)$. In the present contribution, we will describe the effects of perturbed hemodynamic forces on vessel wall remodeling with a specific focus on the relevance of cellbased-mechanosensing in the etiopathogenesis of several vascular diseases.

\section{Altered shear stress is responsible for endothelium dysfunction and atherosclerotic plaque formation}

Although laminar shear stress is considered crucial for physiological vascular functioning, disturbed or oscillatory flow emerges as an important feature of atherogenesis. Indeed, flow patterns and hemodynamic forces are different inside the vascular system: in the straight parts of the arterial tree, blood shear stress is high and laminar, while, in branches and curvatures, blood flow is disturbed with oscillatory/low shear stress (14). It has been demonstrated that atherosclerotic plaques usually tend to form in areas with low and oscillatory shear stress, probably due to the effects of disturbed flow on the endothelium (15). Indeed, oscillatory shear stress induces changes to endothelial gene expression, cytoskeletal arrangement, leukocyte adhesion, thus promoting an oxidative and inflammatory state in the vessel wall. The first evidence of the direct effect of altered hemodynamic conditions on endothelial structure and function is represented by the striking reorganization of endothelial cell morphology in response to shear stress. In particular, strain stimulation induces endothelial cell elongation and alignment in the direction of applied flow (16). This reorganization of actin fibers and cytoskeletal proteins requires a very short time and reaches maximal levels after $1 \mathrm{~h}$ of stimulation, favoring endothelial cell shape, over locomotion, in confluent monolayers (16). Therefore, in response to shear stress, EC stress fibers align with the direction of the flow (17), and this directionality is strictly determinant for the cellular response, such as proliferation (18). The early response of endothelial cells to altered shear stress is mediated, for example, by flowsensitive ion channels, which are important components of EC mechanosensing system (19). In particular, oscillatory shear stress elicits minimal depolarizing current and increases hyperpolarization in ECs, causing defects in cell membrane polarization and affecting ions influx (19). In this way, the production of molecules and bioactive agents with atheroprotective proprieties, such as oxide nitric (NO), is reduced (Fig. 1) (20). Recently, two transmembrane proteins, Piezo1 and Piezo2, have been identified as essential components of ion channels and new EC mechanosensors (21). Indeed, Piezo 1 channels, expressed by human placental arteries ECs, are activated by shear stress (22). Depletion of these two proteins affects the ability of ECs to align in the direction of shear stress, but not cell vitality, suggesting their possible implication in EC shear stress sensing. Another important player in EC mechanosensing is the glycocalyx, which lines the EC apical surface and is tightly related to atherosclerosis (23). Disturbed shear stress is able to physically displace the glycocalyx, inducing an intracellular response (24). Indeed, this mechanosensor is constituted by an extracellular domain for flow sensing and an intracellular sequence, which is directly connected to the cytoskeleton (24). Glycocalyx responds to external stimuli inducing a re-organization of the actin cytoskeleton and subsequent changes in EC morphology and functions, which lead to atherosclerotic plaque formation (Fig. 1) $(25,26)$. Once these mechanosensors are activated, they are able to transduce mechanical signals by increasing kinase activities and modulating the phosphorylation of many signaling proteins. For example, integrin activation results in the phosphorylation of focal adhesion kinases, paxillin and other mediators, leading to the activation of mitogen-activated protein kinases via Ras GTPase (27). This determines important morphological changes and affects cell proliferation and migration $(28,29)$. Rho family kinases activation

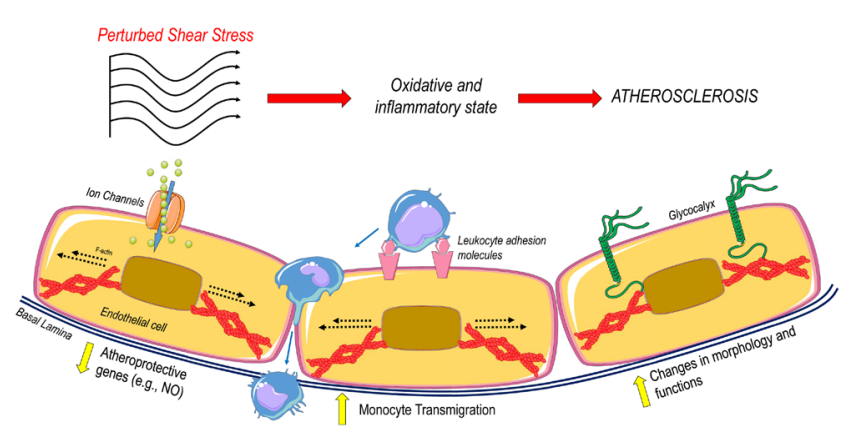

Figure 1

Effects of perturbed shear stress on vascular endothelial cells. Various mechanosensors (ion channels, glycocalyx), expressed at the luminal surface of endothelial cells, are activated by altered blood flow, with consequent changes in cell morphology and functions. This establishes an oxidative and inflammatory state in the endothelium, which promotes atherosclerotic plaque development. 
mediates shear stress dependent-EC alignment, affecting stress fiber formation and cytoskeletal reorganization (30). Therefore, these kinases are also involved in the nuclear import of one of the most important mechanosensitive transcription factors in ECs, Yes associated-protein (YAP). In particular, nuclear YAP is transcriptionally active in human pulmonary artery ECs stimulated with high shear stress, and, in zebrafish, in vivo cessation of blood flow determines the exclusion of YAP from nuclei (31). In addition, it has been shown that disturbed blood flow leads to the nuclear translocation of YAP and consequent continuous activation of its transcriptional machinery. This also explains the increased expression of this factor in atherosclerosis-prone artery regions in mice, which are subject to perturbed shear stress (32). In support to these evidences, the depletion of YAP in mice endothelial cells prevents plaque formation, contributing to quiescent and anti-inflammatory EC phenotype (33). Altered shear stress contributes to establish a chronic inflammation in the endothelium also by inducing the expression of endothelial cell leukocyte adhesion molecules. This is associated with increased monocyte adherence and thus, enhanced vessel wall permeability (Fig. 1) (34). Altered hemodynamic flow is involved in making the pathological conditions worse. On one hand, forming plaque creates sections with perturbed flow inside the vessel, which may favor the rupture of the plaque (35). On the other hand, altered shear stress increases the expression of metalloproteinases (MMPs), promoting fibrous cap collagen degradation and affecting plaque vulnerability (35). The activity of MMPs, a family of proteolytic enzymes involved in ECM components degradation, is regulated by endogenous tissue inhibitors of metalloproteinases (TIMPs) (36). The balance between MMPs and TIMPs plays an important role during late-stage progression and rupture of atherosclerotic plaques. For example, genetic deletion of MMP3 in ApoE mice stimulates the formation of plaques with reduced smooth muscle cell content and concomitant increase in fibrous layers (37). In addition, elevated levels of MMP9 in advanced plaques, associated with macrophage accumulation, do not affect plaque size or composition, but favor plaque disruption by promoting intra-plaque hemorrhages (38). Since endogenous levels of TIMPs are insufficient to contrast MMP activities, one possible therapeutic strategy to contrast flow-mediated plaque instability is to increase the expression of TIMPs (39). Indeed, overexpression of TIMP2 prevents plaque development and disruption, by modulating cellular content and functionalities in mice (40). In particular, TIMP2 interferes with MMPs-mediated atherogenesis by inhibiting SMCs and macrophages-derived foam cells migration and apoptosis (40). The balance between MMPs and TIMPs should be taken into consideration to avoid plaque destabilization driven by perturbed mechanical forces.

Taken together, these evidences highlight that altered shear stress, in conjunction with other risk factors, is able to initiate atherosclerotic plaque formation through the activation of aberrant mechano-dependent machineries, which lead to endothelium dysfunction and pathology.

\section{Cell mechanosensing participates to pro- pathological vessel wall remodeling}

Perturbed shear stress is not the only mechanical stimuli setting pathologic vessel remodeling. In fact, hydrostatic pressure and cyclic strain, due to pressure patterns, are also involved. In particular, altered compression forces, occurring during specific hemodynamic conditions, affect the deeper layers in the vessel wall, such as the media and the adventitia. For example, this is thought to occur in saphenous vein bypass grafts, possibly due to the vein shift from a low and constant flow to a high and pulsatile coronary pattern (41). Indeed, during exposure to arterial conditions, the saphenous vein undergoes a complete vessel wall remodeling, characterized by invasion and overproliferation of vascular smooth muscle cells (VSMCs) in the intima layer (42). These pathological conditions, known as vein graft disease, lead to progressive bypass graft stenosis and consequent ischemic heart disease. Although this pathology has been considered for many years as an endothelial-inflammatory disease, nowadays, recent evidences highlight a strong implication of cell- and tissue-based mechanosensitivity in the initiation of this disease. Indeed, it has been demonstrated that the direct exposure of human saphenous vein to coronary pulsatile pressure causes a complete remodeling of the vessel wall, both at the cell and tissue level (43). In this study, cyclic strain induced a switching of VSMCs from contractile to synthetic phenotype, associated with a consistent release of thrombospondin-1, a pro-fibrotic matricellular protein, with chemoattractant effects on saphenous vein progenitor cells (SVPs) (Fig. 2) (43). In addition, this protein, in conjunction with TGFB1, increased the SVP proliferation rate and collagen production, resulting in myofibroblastlike differentiation of vein progenitor cells (Fig. 2) (43). The direct application of circumferential tension to SVPs revealed a potent mechano-dependent response of these cells, in terms of gene expression pathways involved in

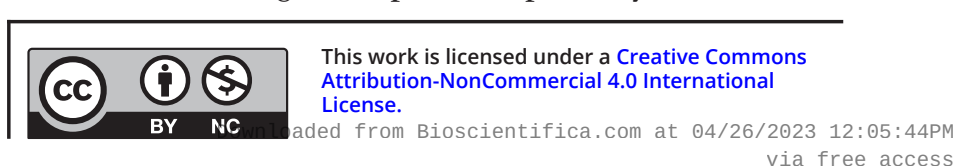




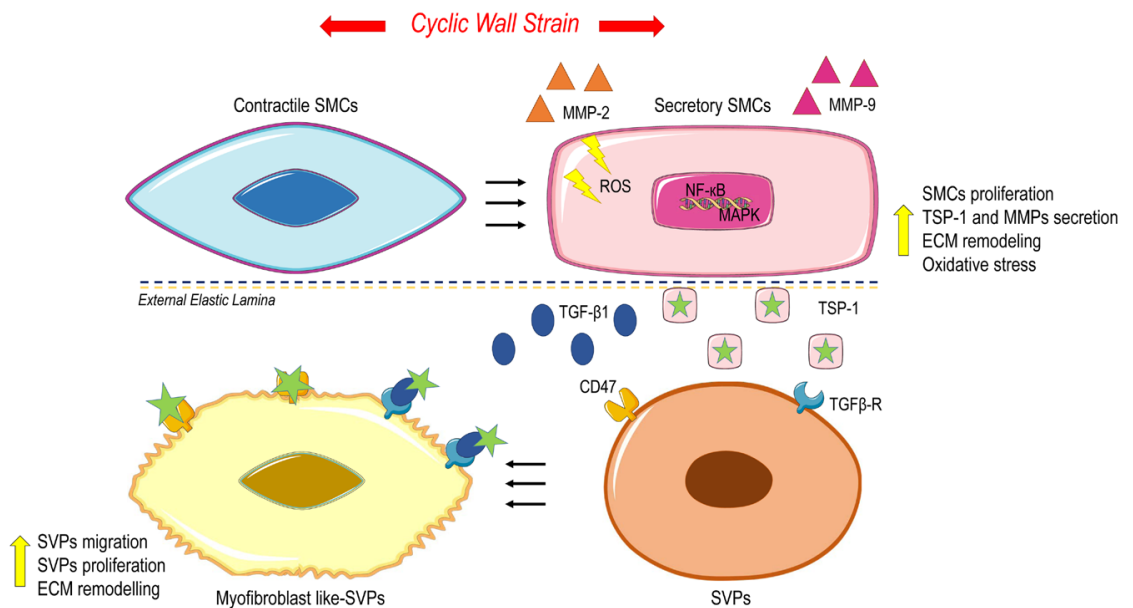

\section{Figure 2}

Effects of cyclic wall strain on vascular smooth muscle cells and adventitial progenitor cells. Vessel wall remodeling is associated with SMCs phenotypic switching and an increased release of TSP-1, a matricellular protein with chemoattractant effects on SVPs. TSP1, in conjunction with TGFB, induces SVPs differentiation into proliferative myofibroblast like-cells deputed to ECM remodeling. In addition, cyclic strain increases smooth muscle cells proliferation, oxidative stress (ROS), and MMPs activities. extracellular matrix remodeling and cell differentiation (Garoffolo et al. data not published). In particular, it has been demonstrated that a mechano-dependent enrichment of YAP/TEAD signature, with particular reference to genes implicated in profibrotic cell activation. Taken together, these evidences highlight the implication of cell and tissue mechanics in the human vein arterialization process. In particular, prolonged altered mechanics could cause remarkable changes in cell structure and gene expression, leading to pro-pathological cell activation and the onset of fibrosis. Beyond its effect on VSMCs phenotypic switching, pulsatile stretch is also able to stimulate SMCs proliferation by increasing oxidative stress and promoting DNA synthesis via NFKB (Fig. 2) (44). Indeed, direct exposure of SMCs to cyclic strain elicits a rapid increase in intracellular NAD phosphate $(\mathrm{NAD}(\mathrm{P}) \mathrm{H})$, associated with elevated levels of reactive oxygen species (ROS, superoxide, and hydrogen peroxide) (Fig. 2) (45). One signaling target of oxidative stress is mediated by the mitogen-activated protein kinase (MAPK) family. In particular, extracellular signal-regulated protein kinase (ERK)1/2, p38 MAPK, and c-jun N-terminal kinase (JNK) are all activated by cyclic strain in SMCs and specifically inhibited by a specific $\mathrm{NAD}(\mathrm{P}) \mathrm{H}$ inhibitor, suggesting the implication of redox-sensitive signaling pathways activated by mechanical strain (45). Exposure of VSMCs to cyclic mechanical strain also increases collagen and fibronectin concentrations, metalloproteinases activity, and the release of TGFB1, modulating in this way the fibrogenic activity of VSMCs (Fig. 2) (46, 47). However, SMCs derived from the internal mammary artery (IMA) or saphenous vein (SV) have different behavior under mechanical stimulation; pulsatile strain affects cell proliferation in SV, but not IMA, suggesting that mechanical factors are potential mediators of aberrant cell proliferation during vein graft occlusion (48).

Mechanically strained VSMCs are also known to directly impact the vessel wall structure and organization by ECM production and deposition. In physiological conditions, VSMCs are surrounded by ECM consisting of collagens, elastin, and proteoglycans, all necessary to maintain vascular tissue integrity (49). Changes in hemodynamic forces increase the expression of enzymes involved in tissue remodeling and collagen production $(50,51)$, which are able to affect the structural composition of the vessel. Indeed, elevated cyclic strain is able to upregulate the production of matrix-degrading enzymes (MMPs 2 and 9) and the release of inflammatory and remodeling factors by VSMCs, such as TGFB, angiotensin II, all associated with aneurismatic dilatation of the aorta (52, 53). Indeed, abnormal SMC mechanosensing has been implicated in thoracic aortic aneurysm progression (TAA) in a variety of genetically driven diseases (52); for example, Marfan syndrome, a heritable disorder of connective tissue, caused by mutations in fibrillin- 1 gene (FBN1) (54). This protein is essential for the formation of elastic fibers, and mutations in this gene affect ECM integrity at the level of tunica media, in the aorta, leading to TAA and dissection (54). FBN1 mutation determines an altered mechanical compliance of the matrix, thus resulting in VSMCs morphological and functional changes (phenotypic switching and apoptosis), leading to aortic wall degradation (55). Stanford type A aortic dissection (STAAD) pathogenesis is characterized by changes in ECM mechanical stress and consequent VSMCs apoptosis, due to aortic media degeneration (56). How this disorganized mechanical stress contributes to (c) 2020 The authors Published by Bioscientifica Ltd

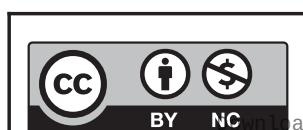

This work is licensed under a Creative Commons Attribution-NonCommercial 4.0 International License. ded from Bioscientifica.com at 04/26/2023 12:05:44PM 
VSMCs apoptosis and the pathology remains unclear, but recent evidences suggest the implication of YAP-related mechanosensing pathway also in this disease. Indeed, the deletion of vascular smooth muscle-specific Yap in mice results in embryonic lethality with abnormal aorta development (57), and, in addition, altered mechanical stress is able to affect YAP expression (58). In normal aortas, YAP is mainly expressed by VSMCs at the level of the tunica media; instead, in the mouse model of STAAD, the expression of this transcription factor is completely reduced and it is negatively correlated with the ascending aorta diameter $(59,60)$. These results suggest that low mechanical compliance of the aortic matrix may cause YAP nuclear exclusion and degradation, making it transcriptionally inactive. This could also explain the increase of VSMCs apoptosis and the parallel downregulation of cell proliferation, one of the main YAP-mediated cell functionings. Also, elevated wall pressure can play an important role in the onset of vascular diseases. For example, cyclic strain induces arterial stiffening of large arteries, contributing to vascular calcification. Indeed, due to calcific plaque that affects vessel patency, the velocity of the blood flow increases with consequent effects on blood pressure (61). High pulsatile pressure affects VSMCs that actively differentiate to remodel arterial tissues after injury. Within the tunica media, undifferentiated VSMCs can shift phenotypically to osteoclast-like cells after environmental stimuli, such as increased matrix stiffness and elevated mechanical strain (62). Indeed, abnormal mechanical strain induces the overproduction of collagen and fragmentation of elastin fibers, causing complete structural disorganization of the vessel wall and a reduced vessel elasticity (63). This determines an increased matrix stiffness of the vessel and consequently an over-proliferation of hypercontractile SMC population with osteochondrogenic features (62). In addition to altered actomyosin activity, matrix stiffness is able to influence also VSMCs differentiation, creating in this way a feedback loop, which overstimulates remodeling processes and may be responsible for the growth of calcific plaque (64). WNT/ $\beta$-catenin signaling plays a crucial role in arterial medial calcification, through the induction of Runx2, which, in turn, regulates VSMCs osteoblast transdifferentiation in the high-phosphate environment (65). Inhibition of $\mathrm{WNT} / \beta$-catenin signaling using WNT antagonist, DKK1, abolishes calcium deposition stimulated by high-phosphate in VSMC (65). It is possible to speculate that pro-pathological VSMCs differentiation is affected by mechanical strain and matrix stiffness and targeting WNT/ $\beta$-catenin signaling could be an effective strategy to prevent arterial medial calcification.

\section{Conclusions}

Hemodynamic forces play a crucial role both in vascular morphogenesis and disease. Vascular cells are able to respond to mechanical stimulation activating intracellular signaling pathways and regulating gene expression. Aberrant cell mechanosensing, in conjunction with metabolic, genetic and inflammatory risk factors, could be implicated in the initiation of several vascular diseases. Taken together, these evidences suggest the importance to better define the mechano-dependent mechanisms underlying these pathologies, in order to develop new therapeutic strategies for the treatment of vascular diseases.

\section{Declaration of interest}

The authors declare that there is no conflict of interest that could be perceived as prejudicing the impartiality of this review.

\section{Funding}

This manuscript has been supported by Ricerca Corrente and 5 per mille (both funded from Italian Ministry of Health) grants issued to M P.

\section{References}

1 Garcia MD \& Larina IV. Vascular development and hemodynamic force in the mouse yolk sac. Frontiers in Physiology 20145 308. (https:// doi.org/10.3389/fphys.2014.00308)

2 May SR, Stewart NJ, Chang W \& Peterson AS. A Titin mutation defines roles for circulation in endothelial morphogenesis. Developmental Biology 2004270 31-46. (https://doi.org/10.1016/j.ydbio.2004.02.006)

3 Huang C, Sheikh F, Hollander M, Cai C, Becker D, Chu PH, Evans S \& Chen J. Embryonic atrial function is essential for mouse embryogenesis, cardiac morphogenesis and angiogenesis. Development 2003130 6111-6119. (https://doi.org/10.1242/dev.00831)

4 Zhong TP, Childs S, Leu JP \& Fishman MC. Gridlock signalling pathway fashions the first embryonic artery. Nature 2001 414 216-220. (https://doi.org/10.1038/35102599)

5 Bai J, Wang YJ, Liu L \& Zhao YL. Ephrin B2 and EphB4 selectively mark arterial and venous vessels in cerebral arteriovenous malformation. Journal of International Medical Research 201442 405-415. (https://doi. org/10.1177/0300060513478091)

6 Obi S, Yamamoto K, Shimizu N, Kumagaya S, Masumura T, Sokabe T, Asahara T \& Ando J. Fluid shear stress induces arterial differentiation of endothelial progenitor cells. Journal of Applied Physiology 2009106 203-211. (https://doi.org/10.1152/japplphysiol.00197.2008)

7 Lee J, Packard RR \& Hsiai TK. Blood flow modulation of vascular dynamics. Current Opinion in Lipidology 201526 376-383. (https://doi. org/10.1097/MOL.0000000000000218) (c) 2020 The authors Published by Bioscientifica Ltd
This work is licensed under a Creative Commons Attribution-NonCommercial 4.0 International License. ded from Bioscientifica.com at 04/26/2023 12:05:44PM 
8 Topper JN \& Gimbrone MA, Jr. Blood flow and vascular gene expression: fluid shear stress as a modulator of endothelial phenotype. Molecular Medicine Today 19995 40-46. (https://doi.org/10.1016/s13574310(98)01372-0)

9 Dekker RJ, van Soest S, Fontijn RD, Salamanca S, de Groot PG, VanBavel E, Pannekoek H \& Horrevoets AJ. Prolonged fluid shear stress induces a distinct set of endothelial cell genes, most specifically lung Kruppel-like factor (KLF2). Blood 2002100 1689-1698. (https://doi. org/10.1182/blood-2002-01-0046)

10 Dekker RJ, van Thienen JV, Rohlena J, de Jager SC, Elderkamp YW, Seppen J, de Vries CJ, Biessen EA, van Berkel TJ, Pannekoek H, et al. Endothelial KLF2 links local arterial shear stress levels to the expression of vascular tone-regulating genes. American Journal of Pathology 2005167 609-618. (https://doi.org/10.1016/S00029440(10)63002-7)

11 Garoffolo G, Madonna R, de Caterina R \& Pesce M. Cell based mechanosensing in vascular patho-biology: more than a simple go-with the flow. Vascular Pharmacology 2018111 7-14. (https://doi. org/10.1016/j.vph.2018.06.013)

12 Garoffolo G \& Pesce M. Mechanotransduction in the cardiovascular system: From developmental origins to homeostasis and pathology. Cells 20198 1607. (https://doi.org/10.3390/cells8121607)

13 Garoffolo G, Ferrari S, Rizzi S, Barbuto M, Bernava G \& Pesce M. Harnessing mechanosensation in next generation cardiovascular tissue engineering. Biomolecules 202010 1419. (https://doi. org/10.3390/biom10101419)

$14 \mathrm{Ku}$ DN, Giddens DP, Zarins CK \& Glagov S. Pulsatile flow and atherosclerosis in the human carotid bifurcation. Positive correlation between plaque location and low oscillating shear stress. Arteriosclerosis 19855 293-302. (https://doi.org/10.1161/01.atv.5.3.293)

15 Xing R, Moerman AM, Ridwan Y, Daemen MJ, van der Steen AFW, Gijsen FJH \& van der Heiden K. Temporal and spatial changes in wall shear stress during atherosclerotic plaque progression in mice. Royal Society Open Science 20185 171447. (https://doi.org/10.1098/ rsos.171447)

16 Osborn EA, Rabodzey A, Dewey CF, Jr \& Hartwig JH. Endothelial actin cytoskeleton remodeling during mechanostimulation with fluid shear stress. American Journal of Physiology: Cell Physiology 2006290 C444-C452. (https://doi.org/10.1152/ajpcell.00218.2005)

17 Girard PR \& Nerem RM. Shear stress modulates endothelial cell morphology and F-actin organization through the regulation of focal adhesion-associated proteins. Journal of Cellular Physiology 1995163 179-193. (https://doi.org/10.1002/jcp.1041630121)

18 Chakraborty A, Chakraborty S, Jala VR, Haribabu B, Sharp MK \& Berson RE. Effects of biaxial oscillatory shear stress on endothelial cell proliferation and morphology. Biotechnology and Bioengineering 2012 109 695-707. (https://doi.org/10.1002/bit.24352)

19 Lieu DK, Pappone PA \& Barakat AI. Differential membrane potential and ion current responses to different types of shear stress in vascular endothelial cells. American Journal of Physiology: Cell Physiology 2004 286 C1367-C1375. (https://doi.org/10.1152/ajpcell.00243.2003)

20 Harmon KJ, Couper LL \& Lindner V. Strain-dependent vascular remodeling phenotypes in inbred mice. American Journal of Pathology 2000156 1741-1748. (https://doi.org/10.1016/S00029440(10)65045-6)

21 Coste B, Mathur J, Schmidt M, Earley TJ, Ranade S, Petrus MJ, Dubin AE \& Patapoutian A. Piezo1 and Piezo2 are essential components of distinct mechanically activated cation channels. Science 2010330 55-60. (https://doi.org/10.1126/science.1193270)

22 Morley LC, Shi J, Gaunt HJ, Hyman AJ, Webster PJ, Williams C, Forbes K, Walker JJ, Simpson NAB \& Beech DJ. Piezo1 channels are mechanosensors in human fetoplacental endothelial cells. Molecular Human Reproduction 201824 510-520. (https://doi.org/10.1093/ molehr/gay033)

23 Lusis AJ. Atherosclerosis. Nature 2000407 233-241. (https://doi. org/10.1038/35025203)
24 Davies PF, Mundel T \& Barbee KA. A mechanism for heterogeneous endothelial responses to flow in vivo and in vitro. Journal of Biomechanics 199528 1553-1560. (https://doi.org/10.1016/00219290(95)00102-6)

25 Yoneda A \& Couchman JR. Regulation of cytoskeletal organization by syndecan transmembrane proteoglycans. Matrix Biology 200322 25-33. (https://doi.org/10.1016/s0945-053x(03)00010-6)

26 Baeyens N, Mulligan-Kehoe MJ, Corti F, Simon DD, Ross TD Rhodes JM, Wang TZ, Mejean CO, Simons M, Humphrey J, et al. Syndecan 4 is required for endothelial alignment in flow and atheroprotective signaling. PNAS 2014111 17308-17313. (https://doi org/10.1073/pnas.1413725111)

27 Shyy JY \& Chien S. Role of integrins in endothelial mechanosensing of shear stress. Circulation Research 200291 769-775. (https://doi org/10.1161/01.res.0000038487.19924.18)

28 Azuma N, Akasaka N, Kito H, Ikeda M, Gahtan V, Sasajima T \& Sumpio BE. Role of p38 MAP kinase in endothelial cell alignment induced by fluid shear stress. American Journal of Physiology: Heart and Circulatory Physiology 2001280 H189-H197. (https://doi.org/10.1152/ ajpheart.2001.280.1.H189)

29 Ji Q, Wang YL, Xia LM, Yang Y, Wang CS \& Mei YQ. High shear stress suppresses proliferation and migration but promotes apoptosis of endothelial cells co-cultured with vascular smooth muscle cells via down-regulating MAPK pathway. Journal of Cardiothoracic Surgery 2019 14 216. (https://doi.org/10.1186/s13019-019-1025-5)

30 Wang Y, Miao H, Li S, Chen KD, Li YS, Yuan S, Shyy JY \& Chien S. Interplay between integrins and FLK-1 in shear stress-induced signaling. American Journal of Physiology: Cell Physiology 2002283 C1540-C1547. (https://doi.org/10.1152/ajpcell.00222.2002)

31 Nakajima H, Yamamoto K, Agarwala S, Terai K, Fukui H, Fukuhara S, Ando K, Miyazaki T, Yokota Y, Schmelzer E, et al. Flow-dependent endothelial YAP regulation contributes to vessel maintenance. Developmental Cell 201740 523.e6-536.e6. (https://doi.org/10.1016/j. devcel.2017.02.019)

32 Wang KC, Yeh YT, Nguyen P, Limqueco E, Lopez J, Thorossian S, Guan KL, Li YJ \& Chien S. Flow-dependent YAP/TAZ activities regulate endothelial phenotypes and atherosclerosis. PNAS 2016113 11525-11530. (https://doi.org/10.1073/pnas.1613121113)

33 Xu S, Koroleva M, Yin M \& Jin ZG. Atheroprotective laminar flow inhibits Hippo pathway effector YAP in endothelial cells Translational Research 2016176 18.e2-28.e2. (https://doi.org/10.1016/j. trsl.2016.05.003)

34 Chappell DC, Varner SE, Nerem RM, Medford RM \& Alexander RW. Oscillatory shear stress stimulates adhesion molecule expression in cultured human endothelium. Circulation Research 1998 82 532-539. (https://doi.org/10.1161/01.res.82.5.532)

35 Pedrigi RM, de Silva R, Bovens SM, Mehta VV, Petretto E \& Krams R. Thin-cap fibroatheroma rupture is associated with a fine interplay of shear and wall stress. Arteriosclerosis, Thrombosis, and Vascular Biology 201434 2224-2231. (https://doi.org/10.1161/ATVBAHA.114.303426)

36 Raffetto JD \& Khalil RA. Matrix metalloproteinases and their inhibitors in vascular remodeling and vascular disease. Biochemical Pharmacology 200875 346-359. (https://doi.org/10.1016/j.bcp.2007.07.004)

37 Johnson JL, George SJ, Newby AC \& Jackson CL. Divergent effects of matrix metalloproteinases $3,7,9$, and 12 on atherosclerotic plaque stability in mouse brachiocephalic arteries. PNAS 2005102 15575-15580. (https://doi.org/10.1073/pnas.0506201102)

38 Gough PJ, Gomez IG, Wille PT \& Raines EW. Macrophage expression of active MMP-9 induces acute plaque disruption in apoE-deficient mice. Journal of Clinical Investigation 2006116 59-69. (https://doi. org/10.1172/JCI25074)

39 Fabunmi RP, Sukhova GK, Sugiyama S \& Libby P. Expression of tissue inhibitor of metalloproteinases-3 in human atheroma and regulation in lesion-associated cells: a potential protective mechanism in plaque stability. Circulation Research 199883 270-278. (https://doi. org/10.1161/01.res.83.3.270) 
40 Johnson JL, Baker AH, Oka K, Chan L, Newby AC, Jackson CL \& George SJ. Suppression of atherosclerotic plaque progression and instability by tissue inhibitor of metalloproteinase-2: involvement of macrophage migration and apoptosis. Circulation 2006113 2435-2444. (https://doi.org/10.1161/CIRCULATIONAHA.106.613281)

41 Berard X, Deglise S, Alonso F, Saucy F, Meda P, Bordenave L, Corpataux JM \& Haefliger JA. Role of hemodynamic forces in the ex vivo arterialization of human saphenous veins. Journal of Vascular Surgery 201357 1371-1382. (https://doi.org/10.1016/j.jvs.2012.09.041)

42 Newby AC. Coronary vein grafting: the flags keep waving but the game goes on. Cardiovascular Research 201397 193-194. (https://doi org/10.1093/cvr/cvs351)

43 Garoffolo G, Ruiter MS, Piola M, Brioschi M, Thomas AC, Agrifoglio M, Polvani G, Coppadoro L, Zoli S, Saccu C, et al. Coronary artery mechanics induces human saphenous vein remodelling via recruitment of adventitial myofibroblast-like cells mediated by Thrombospondin-1. Theranostics 202010 2597-2611. (https://doi. org/10.7150/thno.40595)

44 Hishikawa K, Oemar BS, Yang Z \& Luscher TF. Pulsatile stretch stimulates superoxide production and activates nuclear factor-kappa B in human coronary smooth muscle. Circulation Research $1997 \mathbf{8 1}$ 797-803. (https://doi.org/10.1161/01.res.81.5.797)

45 Chen Q, Li W, Quan Z \& Sumpio BE. Modulation of vascular smooth muscle cell alignment by cyclic strain is dependent on reactive oxygen species and P38 mitogen-activated protein kinase. Journal of Vascular Surgery 200337 660-668. (https://doi.org/10.1067/mva.2003.95)

46 O'Callaghan CJ \& Williams B. Mechanical strain-induced extracellular matrix production by human vascular smooth muscle cells: role of TGF-beta(1). Hypertension 200036 319-324. (https://doi. org/10.1161/01.hyp.36.3.319)

47 Stanley AG, Patel H, Knight AL \& Williams B. Mechanical straininduced human vascular matrix synthesis: the role of angiotensin II. Journal of the Renin-Angiotensin-Aldosterone System 20001 32-35. (https://doi.org/10.3317/jraas.2000.007)

48 Predel HG, Yang Z, von Segesser L, Turina M, Buhler FR \& Luscher TF. Implications of pulsatile stretch on growth of saphenous vein and mammary artery smooth muscle. Lancet $1992 \mathbf{3 4 0} 878-879$. (https:// doi.org/10.1016/0140-6736(92)93287-w)

49 Stegemann JP, Hong H \& Nerem RM. Mechanical, biochemical, and extracellular matrix effects on vascular smooth muscle cell phenotype. Journal of Applied Physiology 200598 2321-2327. (https://doi. org/10.1152/japplphysiol.01114.2004)

50 Seliktar D, Nerem RM \& Galis ZS. Mechanical strainstimulated remodeling of tissue-engineered blood vesse constructs. Tissue Engineering 20039 657-666. (https://doi. org/10.1089/107632703768247359)

51 Seliktar D, Nerem RM \& Galis ZS. The role of matrix metalloproteinase- 2 in the remodeling of cell-seeded vascular constructs subjected to cyclic strain. Annals of Biomedical Engineering 200129 923-934. (https://doi.org/10.1114/1.1415522)

52 Yamashiro Y, Papke CL, Kim J, Ringuette LJ, Zhang QJ, Liu ZP, Mirzaei H, Wagenseil JE, Davis EC \& Yanagisawa H. Abnormal mechanosensing and cofilin activation promote the progression of ascending aortic aneurysms in mice. Science Signaling 20158 ra105. (https://doi.org/10.1126/scisignal.aab3141)

53 Asanuma K, Magid R, Johnson C, Nerem RM \& Galis ZS. Uniaxial strain upregulates matrix-degrading enzymes produced by human vascular smooth muscle cells. American Journal of Physiology: Heart and Circulatory Physiology 2003284 H1778-H1784. (https://doi. org/10.1152/ajpheart.00494.2002)

54 Yuan SM \& Jing H. Marfan's syndrome: an overview. Sao Paulo Medical Journal 2010128 360-366. (https://doi.org/10.1590/s151631802010000600009)

55 Perrucci GL, Rurali E, Gowran A, Pini A, Antona C, Chiesa R, Pompilio G \& Nigro P. Vascular smooth muscle cells in Marfan syndrome aneurysm: the broken bricks in the aortic wall. Cellular and Molecular Life Sciences 201774 267-277. (https://doi.org/10.1007/ s00018-016-2324-9)

56 Sayantan J, Mei H, Mengchen S \& Zamaneh K. Extracellular matrix, regional heterogeneity of the aorta, and aortic aneurysm. Experimental \& molecular medicine 201951 1-15. (https://doi.org/10.1038/s12276019-0286-3)

57 Wang Y, Hu G, Liu F, Wang X, Wu M, Schwarz JJ \& Zhou J. Deletion of yes-associated protein (YAP) specifically in cardiac and vascular smooth muscle cells reveals a crucial role for YAP in mouse cardiovascular development. Circulation Research 2014114 957-965. (https://doi.org/10.1161/CIRCRESAHA.114.303411)

58 Santoro R, Scaini D, Severino LU, Amadeo F, Ferrari S, Bernava G, Garoffolo G, Agrifoglio M, Casalis L \& Pesce M. Activation of human aortic valve interstitial cells by local stiffness involves YAP-dependent transcriptional signaling. Biomaterials 2018181 268-279. (https://doi. org/10.1016/j.biomaterials.2018.07.033)

59 Jiang WJ, Ren WH, Liu XJ, Liu Y, Wu FJ, Sun LZ, Lan F, Du J \& Zhang HJ. Disruption of mechanical stress in extracellular matrix is related to Stanford type A aortic dissection through down-regulation of yes-associated protein. Aging 20168 1923-1939. (https://doi. org/10.18632/aging.101033)

60 Li H, Jiang W, Ren W, Guo D, Guo J, Wang X, Liu Y, Lan F, Du J $\&$ Zhang H. Downregulation of the yes-associated protein is associated with extracellular matrix disorders in ascending aortic aneurysms. Stem Cells International 20162016 6786184. (https://doi. org/10.1155/2016/6786184)

61 He F, Hua L \& Gao LJ. A computational model for biomechanical effects of arterial compliance mismatch. Applied Bionics and Biomechanics 20152015 213236. (https://doi. org/10.1155/2015/213236)

62 Van den Bergh G, Opdebeeck B, D’Haese PC \& Verhulst A. The vicious cycle of arterial stiffness and arterial media calcification. Trends in Molecular Medicine 201925 1133-1146. (https://doi.org/10.1016/j. molmed.2019.08.006)

$63 \mathrm{Xu}$ C, Zarins CK, Pannaraj PS, Bassiouny HS \& Glagov S. Hypercholesterolemia superimposed by experimental hypertension induces differential distribution of collagen and elastin. Arteriosclerosis, Thrombosis, and Vascular Biology 200020 2566-2572. (https://doi.org/10.1161/01.atv.20.12.2566)

64 Ngai D, Lino M \& Bendeck MP. Cell-matrix interactions and Matricrine signaling in the pathogenesis of vascular calcification. Frontiers in Cardiovascular Medicine 20185 174. (https://doi.org/10.3389/ fcvm.2018.00174)

65 Cai T, Sun D, Duan Y, Wen P, Dai C, Yang J \& He W. WNT/beta-catenin signaling promotes VSMCs to osteogenic transdifferentiation and calcification through directly modulating Runx2 gene expression. Experimental Cell Research 2016345 206-217. (https://doi.org/10.1016/j. yexcr.2016.06.007)

Received in final form 24 May 2021

Accepted 9 June 2021

Accepted Manuscript published online 9 June 2021 (c) 2020 The authors Published by Bioscientifica Ltc

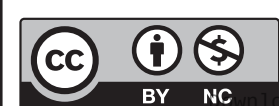

This work is licensed under a Creative Commons Attribution-NonCommercial 4.0 International License. led from Bioscientifica com at 04/26/2023 12:05:44PM 